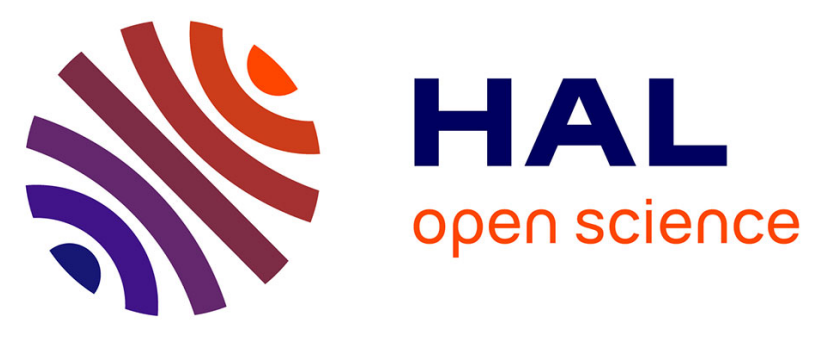

\title{
The numerical simulation of heat transfer during a hybrid laser-MIG welding using equivalent heat source approach
}

Issam Bendaoud, Simone Mattei, Eugen Cicala, Iryna Tomashchuk, Henri Andrzejewski, Pierre Sallamand, Alexandre Mathieu, Fréderic Bouchaud

\section{To cite this version:}

Issam Bendaoud, Simone Mattei, Eugen Cicala, Iryna Tomashchuk, Henri Andrzejewski, et al.. The numerical simulation of heat transfer during a hybrid laser-MIG welding using equivalent heat source approach. Optics and Laser Technology, 2014, 56, pp.334-342. 10.1016/j.optlastec.2013.09.007 . hal01951593

\section{HAL Id: hal-01951593 \\ https://hal.science/hal-01951593}

Submitted on 11 Dec 2018

HAL is a multi-disciplinary open access archive for the deposit and dissemination of scientific research documents, whether they are published or not. The documents may come from teaching and research institutions in France or abroad, or from public or private research centers.
L'archive ouverte pluridisciplinaire HAL, est destinée au dépôt et à la diffusion de documents scientifiques de niveau recherche, publiés ou non, émanant des établissements d'enseignement et de recherche français ou étrangers, des laboratoires publics ou privés. 


\title{
The numerical simulation of heat transfer during a hybrid laser-MIG welding using equivalent heat source approach
}

\author{
Issam Bendaoud $^{\text {a,*, Simone Matteï }}{ }^{a}$, Eugen Cicala ${ }^{a}$, Iryna Tomashchuk ${ }^{a}$, \\ Henri Andrzejewski ${ }^{a}$, Pierre Sallamand ${ }^{a}$, Alexandre Mathieu ${ }^{a}$, Fréderic Bouchaud ${ }^{b}$ \\ ${ }^{a}$ Laboratoire Interdisciplinaire Carnot de Bourgogne, UMR 6303 CNRS/Université de Bourgogne, IUT-12, rue de la Fonderie, Le Creusot 71200, France bentre de Recherche des \\ Matériaux du Creusot, Arcelor Mittal France/Industeel, 56 rue Clémenceau, Le Creusot 71200, France
}

\begin{abstract}
A B S T R A C T
The present study is dedicated to the numerical simulation of an industrial case of hybrid laser-MIG welding of high thickness duplex steel UR2507Cu with Y-shaped chamfer geometry. It consists in simulation of heat transfer phenomena using heat equivalent source approach and implementing in finite element software COMSOL Multiphysics. A numerical exploratory designs method is used to identify the heat sources parameters in order to obtain a minimal required difference between the numerical results and the experiment which are the shape of the welded zone and the temperature evolution in different locations. The obtained results were found in good correspondence with experiment, both for melted zone shape and thermal history.
\end{abstract}

Keywords:

Hybrid laser-arc welding

Numerical simulation

Heat transfer

\section{Introduction}

The hybrid laser/MIG welding method allows achieving a synergetic effect from the use of two heat sources. The aim is to combine the advantages of arc welding with those of laser to overcome the limitations of individual processes. The hybrid laser arc welding is reported as having the potential to increase penetration depth, width and so welding speed, whilst improving tolerance and controlling weld pool chemistry by means of filler addition. In our study, the work piece has a thickness of $20 \mathrm{~mm}$. In this case, the laser role is welding the root of the work piece and the MIG process provides for the filling the chamfer. The development of a simulation of this process that would take into account the main involved physical phenomena would be very useful industrial tool for estimating the welding effects (temperature field and melted zone shape) for a given set of operational parameters. Unfortunately, each process alone is not already completely mastered or understood, nor is their combination. Nevertheless, the precise knowledge of thermal history is essential for accurate prediction of the distortions and residual stresses. In order to access to the thermal history in the solid part of the work piece, a method consists in treating the heat transfer by the equivalent heat sources approach. This method does not require the description of all phenomena that occur in the weld pool: it consists in the definition of the heat sources that provide

\footnotetext{
* Corresponding author. Tel.: +33 3857311 15; fax: +33 385731120

E-mail addresses: issam.bendaoud@u-bourgogne.fr, issam.bendaoud@yahoo.fr (I. Bendaoud).
}

the predetermined geometrical characteristics of the fusion zone. A main difficulty in this numerical approach is the choice of the heat sources which will give an adequate representation of each process and the identification of parameters for these sources. This approach is called "equivalent heat source approach". Somme works can be found in the literature using this approach. For instance, Reutzel et al. [1] have proposed a three dimensional thermal finite element model using a volumetric double ellipsoidal heat source to represent both laser and MIG. Le Guen et al. [2] have presented a 3D quasi-steady thermal model for hybrid laser/MAG welding which let to calculate the temperature field in the solid and predicts the melt pool surface by taking into account the addition of filler metal and the effects of surface tension. In the same way, Bidi et al. [3] using this same approach, have determined the thermal field, in the case of a hybrid laser/MIG welding process. The studied process is used to obtain a straight weld bead on a stainless steel plate, in flat position. In their work, the equivalent heat source approach is associated to numerical exploratory designs method in order to estimate the unknown parameters of the analytical sources.

In the last years, the multiphysical approach to the modeling of hybrid welding starts to develop. In opposite to equivalent source approach, that describes only thermal field in the work piece, multiphysical approach is based on detailed description of various phenomena taking place in the weld pool. First, very complete VOF two-dimensional models dealing with metal transfer and melted zone dynamics were proposed: Zhou and Tasi [6] solved thermohydraulic problem in the transversal cut of melted zone when Gao et al. [5] solved this problem on the joint line. Then, Cho and Na [4] proposed three dimensional model providing the information on 
temperature field, pressure balance, melt flow, and free surface evolution. However, these early studies contain very few comparisons with experimental results and are not yet applied to complex welding geometries.

In spite of simpler description of heat transfer phenomenology, equivalent source approach is widely used for industrial applications dealing with complex welding geometries due to shorter calculation times and smaller quantity of enter parameters,.

In this paper, a numerical simulation using the equivalent source approach is applied to the case of hybrid laser/MIG welding in a complex geometry. This model is able to determine the temperature field out of the weld pool and to reproduce the shape of the melted zone. The heat source parameters are calibrated using a numerical exploratory designs method. The numerical results are compared with weld crosscut shapes and thermocouple measurements.

\section{Welding experiment}

\subsection{Welding configuration}

The experimental configuration is shown in Fig. 1. The experiments consist in the realization of a one pass hybrid laser/MIG welding of duplex steel UR2507Cu (Euronorm 1.4507-X2CrNiMoCuN25.6.3) in Y-shaped chamfer geometry. UR2507Cu is a super duplex stainless steel with $25 \% \mathrm{Cr}$ having austeno-ferritic microstructure with a ratio $\gamma / \alpha$ close to balance. The chemical composition is given in Table 1.

The filler wire Sandvik ${ }^{\circledR} 4 \mathrm{~L}-25-10$ with a diameter of $1.2 \mathrm{~mm}$ is used. It is chosen because of chemical composition (Table 2) close to that of the super duplex but containing more $\mathrm{Ni}$, which allows maintaining the recommended quantity of ferrite $(43 \%)$ in the melted zone of MIG.

The experimental work is carried out using a TRUDISK $6002 \mathrm{Yb}$ : YAG laser with a maximum output power of $6 \mathrm{~kW}$, and a FRONIUS torch arc. A FRONIUS head design holds the laser and the MIG torch. In this case, the laser focus position is in front of the arc, this position is defined by two parameters: laser-MIG distance $\left(D_{2}\right)$ and angle between the laser beam and the vertical axis $\left(30^{\circ}\right)$ (Fig. 1). The welding parameters are shown in Table 3.

A high speed camera PHANTOM V9.1 with Cavilux laser diode illumination is used for the visualization of interaction zone. It is positioned in front of the laser, close to the welding axis, and has an inclination of $30^{\circ}$ to the surface of work piece. The camera provides 60 frames per a second at full resolution of $1632 \times 1200$ active pixels. Such shooting frequency was chosen due to the laser illumination characteristics, which is pulsed in a frequency of 60 frames par a second. Fig. 2 shows an example of the frame obtained from a case having the distance laser/MIG of $21 \mathrm{~mm}$. Two separated operating zones can be observed (Fig. 2): the laser weld pool followed by the MIG weld pool. The distance between two melted zones is estimated to $13 \mathrm{~mm}$.

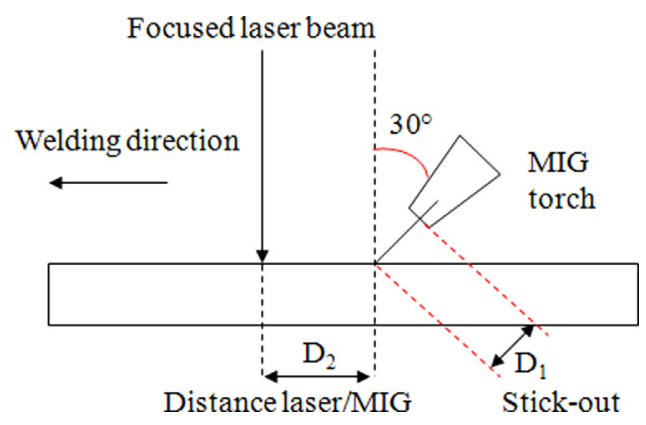

Fig. 1. Joint geometry and laser/MIG layout.
Table 1

Chemical composition of the duplex stainless steel.

\begin{tabular}{llllll}
\hline $\mathrm{C}$ & $\mathrm{Cr}$ & $\mathrm{Ni}$ & $\mathrm{Mo}$ & $\mathrm{N}$ & $\mathrm{Cu}$ \\
\hline 0.03 & 25 & 6.5 & 3.5 & 0.25 & 1.5 \\
\hline
\end{tabular}

Table 2

Chemical composition of filler wire Sandvik ${ }^{\circledR}$ 4L-25-10.

\begin{tabular}{lllllllll}
\hline $\mathrm{C}$ & $\mathrm{Si}$ & $\mathrm{Mn}$ & $\mathrm{P}$ & $\mathrm{S}$ & $\mathrm{Cr}$ & $\mathrm{Ni}$ & $\mathrm{Mo}$ & $\mathrm{N}$ \\
\hline 0.02 & 0.3 & 0.4 & 0.02 & 0.015 & 25 & 9.5 & 4 & 0.24 \\
\hline
\end{tabular}

Table 3

Operational parameters.

\begin{tabular}{ll}
\hline Parameters & Values \\
\hline Laser power [kW] & 6 \\
Laser beam diameter [mm] & 0.2 \\
Wire speed [m/min] & 12 \\
MIG power [kW] & 12.6 \\
Wire diameter [mm] & 1.2 \\
Speed welding [m/min] & 0.4 \\
Distance laser-MIG $D_{2}[\mathrm{~mm}]$ & 21 \\
Distance MIG torch-work piece surface $D_{1}[\mathrm{~mm}]$ & 18 \\
Shielding gas flow in the nozzle: ARCAL $129[\mathrm{~L} / \mathrm{min}]$ & 18 \\
Shielding gas flow in the saddle: ARCAL $129[\mathrm{~L} / \mathrm{min}]$ & 30 \\
Shielding gas flow back side: Argon [L/min] & 10 \\
\hline
\end{tabular}

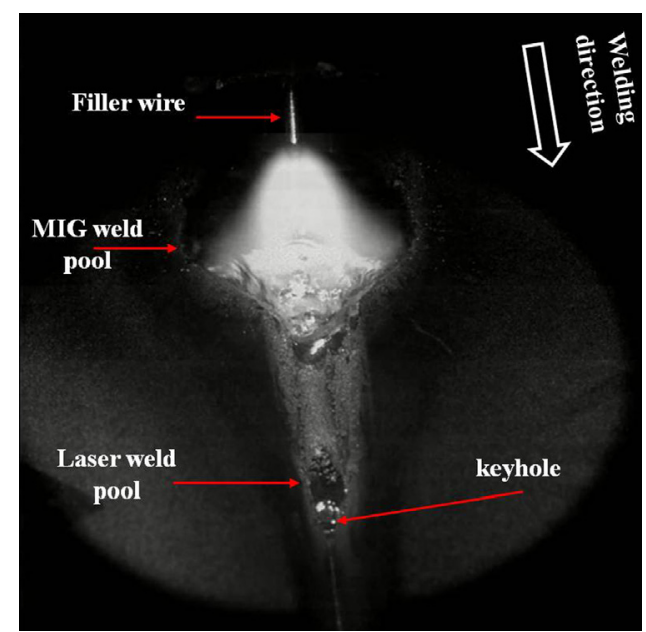

Fig. 2. Front view of interaction zone by high speed camera.

It was found that the distance between laser and MIG sources is a key-parameter for avoiding weld pool collapse. An experiment carried out with laser/MIG distance changed from $21 \mathrm{~mm}$ to $15 \mathrm{~mm}$ showed that the formation of common weld pool leads to the collapse (Fig. 3). The enhanced synergy of two heat sources increases the volume of melted material and therefore the bath does not support its own weight. Liquid metal flows down through the root created by laser. So, for full penetration welding of high thickness pieces, it is needed to keep sufficient distance between heat sources allowing the formation of separate melted zones.

In order to reveal the synergetic effect between laser and MIG sources distanced by $21 \mathrm{~mm}$ comparing to the situation when each source is operating separately, a comparison was made between present hybrid welding configuration and standalone laser and MIG welding in two steps, (Fig. 4). During two step welding, first the root of the work piece is welded by focused laser beam and then, after 

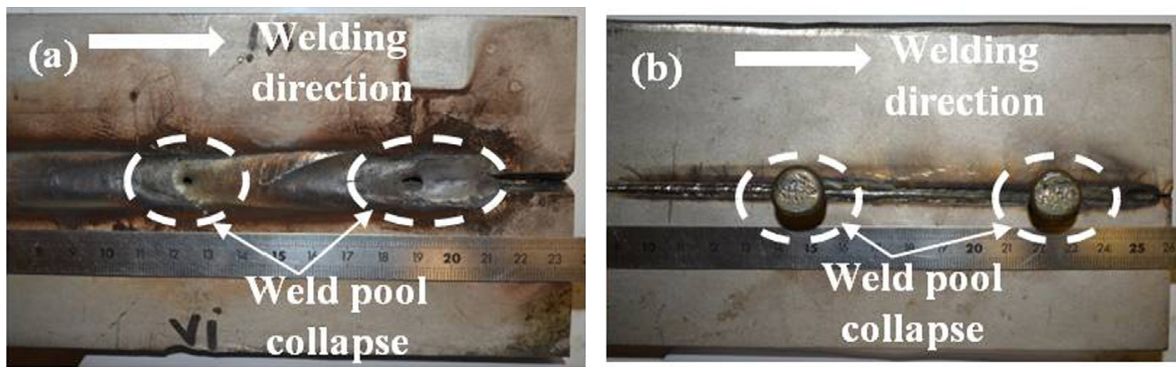

Fig. 3. Weld pool collapse in case of $D_{2}=15 \mathrm{~mm}$ : (a) top view, (b) bottom view.
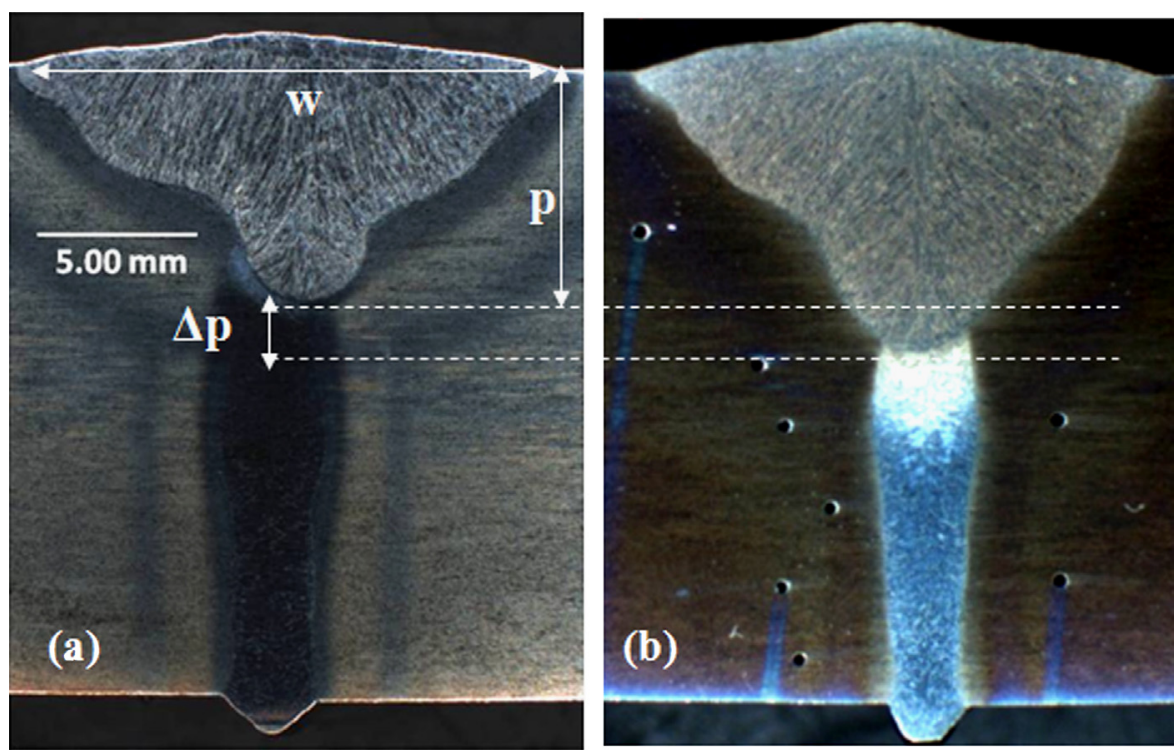

Fig. 4. Transversal cut of the weld performed by (a) two-steps welding, (b) hybrid welding.

cooling the work piece to ambient temperature, the filling of the " $\mathrm{V}$ " chamfer is provided by the MIG process. The comparison of width and full depth penetration of MIG melted zone is made. The measurement results (Table 4) show the difference in melted zone dimensions compared to hybrid welding. The main difference is observed for full depth penetration of the MIG melted zone (p): the average penetration in the hybrid case is equal to $10.3 \mathrm{~mm}$, whereas in the two-step welding the penetration is $7.8 \mathrm{~mm}$. In fact, in hybrid welding, laser passage provides the preheating of " $\mathrm{V}$ " chamfer area and therefore facilitates the fusion of chamfer bottom under action of falling metal droplets. For the width $(w)$, a difference of $1 \mathrm{~mm}$ is observed. So, in spite of laser-MIG distance of $21 \mathrm{~mm}$, the effect of laser heat source on the development of MIG melted zone still exists. However, the laser melted zone remains stable and similar for both welding cases, which means that it is unaffected by MIG heat source.

\subsection{Weld shapes characteristics end temperature measurements}

The welding experiment carried out with operating parameters shown above in Table 3 resulted in full penetration defect free joint. Fig. 5 shows top and bottom surfaces of the weld bead. No defects or humping effect were observed.

In order to verify the constancy of the weld shape, five transversal cuts were prepared (Fig. 6). Although the general appearance of the melted zones shapes remains coherent, we observe some fluctuations in MIG melted zone; however the melted zone due to the laser is stable. These fluctuations phenomena can be attributed on the one hand, to the adjustment of the experimental materials, the MIG torch
Table 4

MIG melted zone dimensions in case of two-step and hybrid welding.

\begin{tabular}{lcc}
\hline & Two step welding & Hybrid welding \\
\hline$w(\mathrm{~mm})$ & $16.8 \pm 0.4$ & $17.9 \pm 0.2$ \\
$p(\mathrm{~mm})$ & $7.8 \pm 0.3$ & $10.3 \pm 0.9$ \\
\hline
\end{tabular}
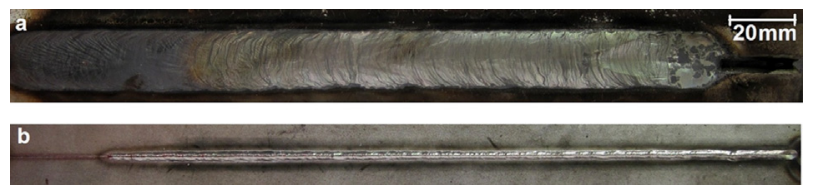

Fig. 5. Hybrid weld bead: (a) top surface, (b) bottom surface.

misalignment towards the welding axis can cause a deviation a the fusion zone, and on the other hand, fluid dynamics of the liquid metal may involve instability in the form of the weld pool. Six measurements shown on Fig. $6 b\left(\mathrm{~L}_{1}, \mathrm{~L}_{2} \ldots\right)$ are made to characterize the geometry of the melted zone. To obtain the temporal evolution of temperature at different points around the melted zone, ten K-type thermocouples (maximal work temperature of $1100{ }^{\circ} \mathrm{C}$ ) have been inserted into holes $(0.5 \mathrm{~mm}$ diameter, $50 \mathrm{~mm}$ deep) machined by electrical discharge. The thermocouples are inserted at the end of the holes and fixed with a heat conducting silver pad. The layout of thermocouples (TC) (Fig. 6a) has been defined in order to record thermal gradients located around and closer to the limit of the melted zone. 

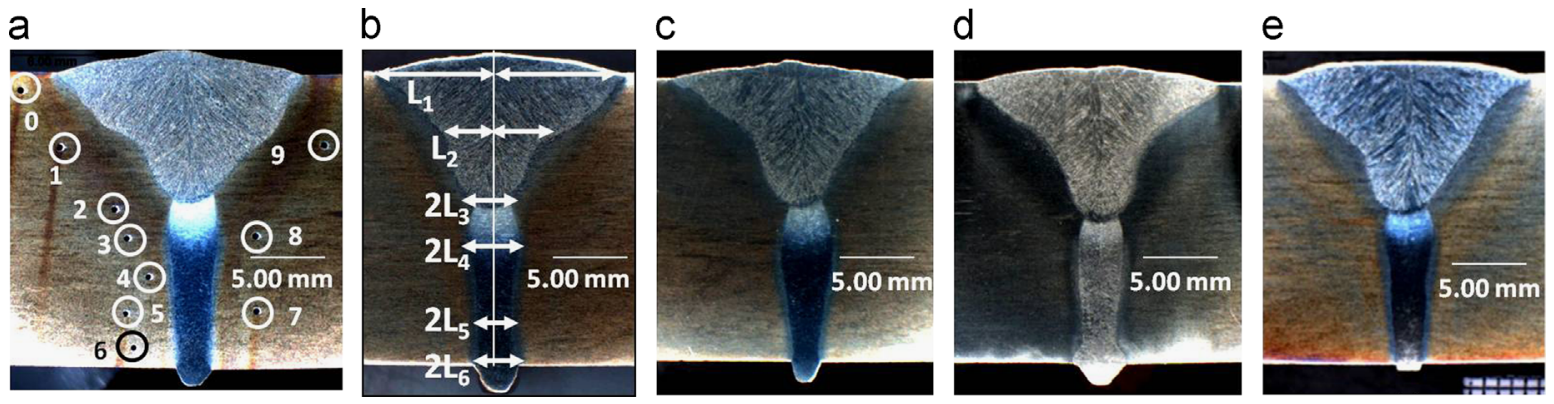

Fig. 6. Transversal cuts with thermocouples layout $\left(T c_{0}-T c_{9}\right)$ and geometrical characteristics of the melted zone $\left(\mathrm{L}_{1}-\mathrm{L}_{6}\right)$.

Table 5

Data used for calculation.

\begin{tabular}{ll}
\hline Physical property & Value \\
\hline Liquidus temperature, $T_{l}(\mathrm{~K})$ & 1748 \\
Solidus temperature, $T_{s}(\mathrm{~K})$ & 1612 \\
Fusion temperature, $T_{f}(\mathrm{~K})$ & 1680 \\
Density of liquid metal, $\rho_{l}\left(\mathrm{~kg} / \mathrm{m}^{3}\right)$ & $-0.6779 T+8113$ \\
Density of solid metal, $\rho_{s}\left(\mathrm{~kg} / \mathrm{m}^{3}\right)$ & $-0.3391 T+7876$ \\
Thermal conductivity of solid, $\lambda_{s}(\mathrm{~W} / \mathrm{m} \mathrm{K})$ & $0.016 T+8.4557$ \\
Equivalent thermal conductivity of liquid, $\lambda_{l}(\mathrm{~W} / \mathrm{m} \mathrm{K})$ & 70 \\
Specific heat of solid, $c p_{s}(\mathrm{~J} / \mathrm{kg} \mathrm{K})$ & $(T<1119 K) 0.5046 T+279.2(T \leq 1119 K) 0.1596 T+459.52$ \\
Specific heat of liquid, $c p_{l}(\mathrm{~J} / \mathrm{kg} \mathrm{K})$ & $0.0646 T+691.14$ \\
Latent heat of melting, $L_{f}(\mathrm{~kJ} / \mathrm{kg})$ & 195 \\
\hline
\end{tabular}

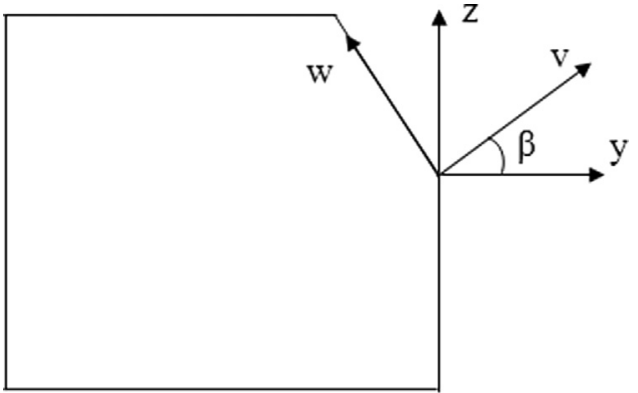

Fig. 7. Coordinates system for $q_{\text {surf1 }}$.

\section{Numerical modeling}

\subsection{Assumptions}

The present model was developed using COMSOL Multiphy$\operatorname{sics}^{\circledR}$ [7]. The numerical model setup is based on the following assumptions:

- Quasi-steady-state conditions: the heat equation is written for a moving coordinate system which moves with the same velocity as the heat source.

- The filler material is supposed to have the same properties that UR2507Cu steel, and the latent heat of fusion is taken into account using the apparent heat capacity formulation [8] as shown in expression (1).

$c_{p}^{e q}=c_{p}+L_{f} \frac{\exp \left(-\frac{\left(T-T_{m}\right)^{2}}{\Delta T^{2}}\right)}{\sqrt{\pi \Delta T^{2}}}$

where $c_{p}$ is the specific heat capacity, $L_{f}$ is the latent heat of fusion, $T_{m}$ is the melting temperature and $\Delta T$ is the difference between solidus and liquidus temperature.

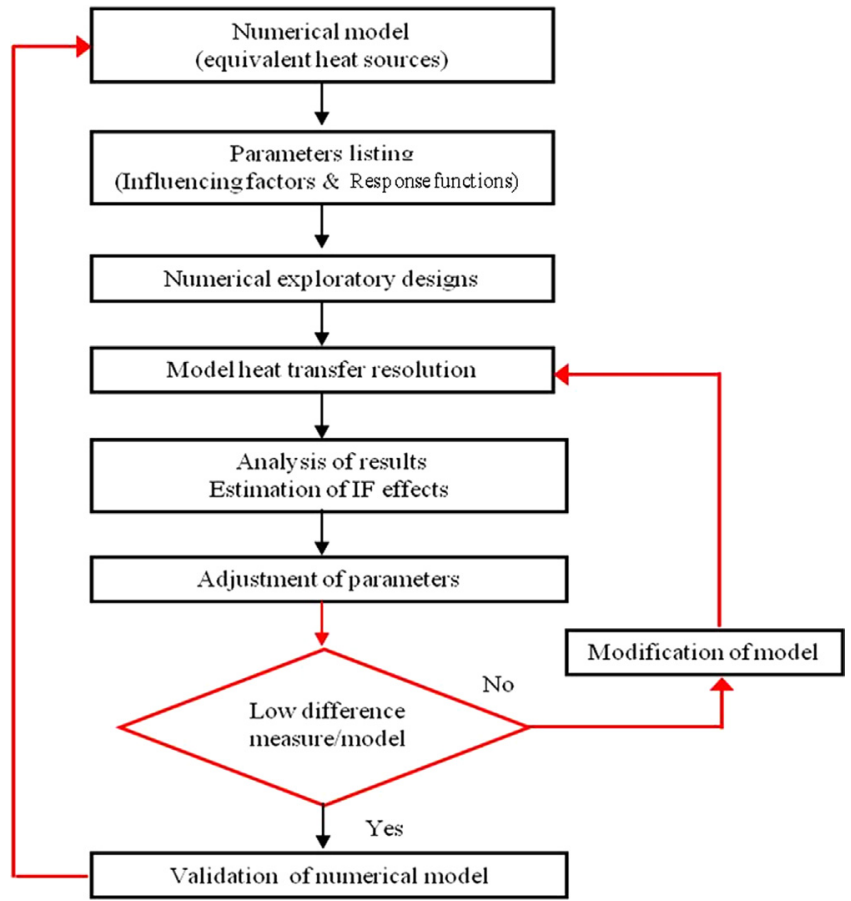

Fig. 8. Flowchart of adjustment of heat source parameters.

- Fluid flow in the weld pool is not considered, but thermal conductivity of the liquid phase is enhanced to take in account convective heat transfer in the weld pool.

- Metallurgical phenomena are not taken into consideration. The values of the latent heat of the metallurgical phase change are generally small compared to solid-liquid latent heat of fusion.

- The weld pool surface is assumed to be in a static equilibrium under action of arc pressure, gravity and surface tension. 
The effect of fluid flow induced by Marangoni phenomena or electromagnetic forces is neglected.

- Only half of the work piece is considered since the weld is symmetrical along the joint centerline. The temperature field is determined by solving the heat Eq. (2) where $Q$ is a sum of volume heat sources.

$\rho(T) c_{p}(T) V_{s} \frac{\partial T}{\partial x}=\operatorname{div}(\lambda(T) \overrightarrow{\operatorname{grad}} T)+Q$

- Finally, to avoid the discontinuity in material properties (thermal conductivity, specific heat capacity and density) during phase transition the smoothed Heaviside function has
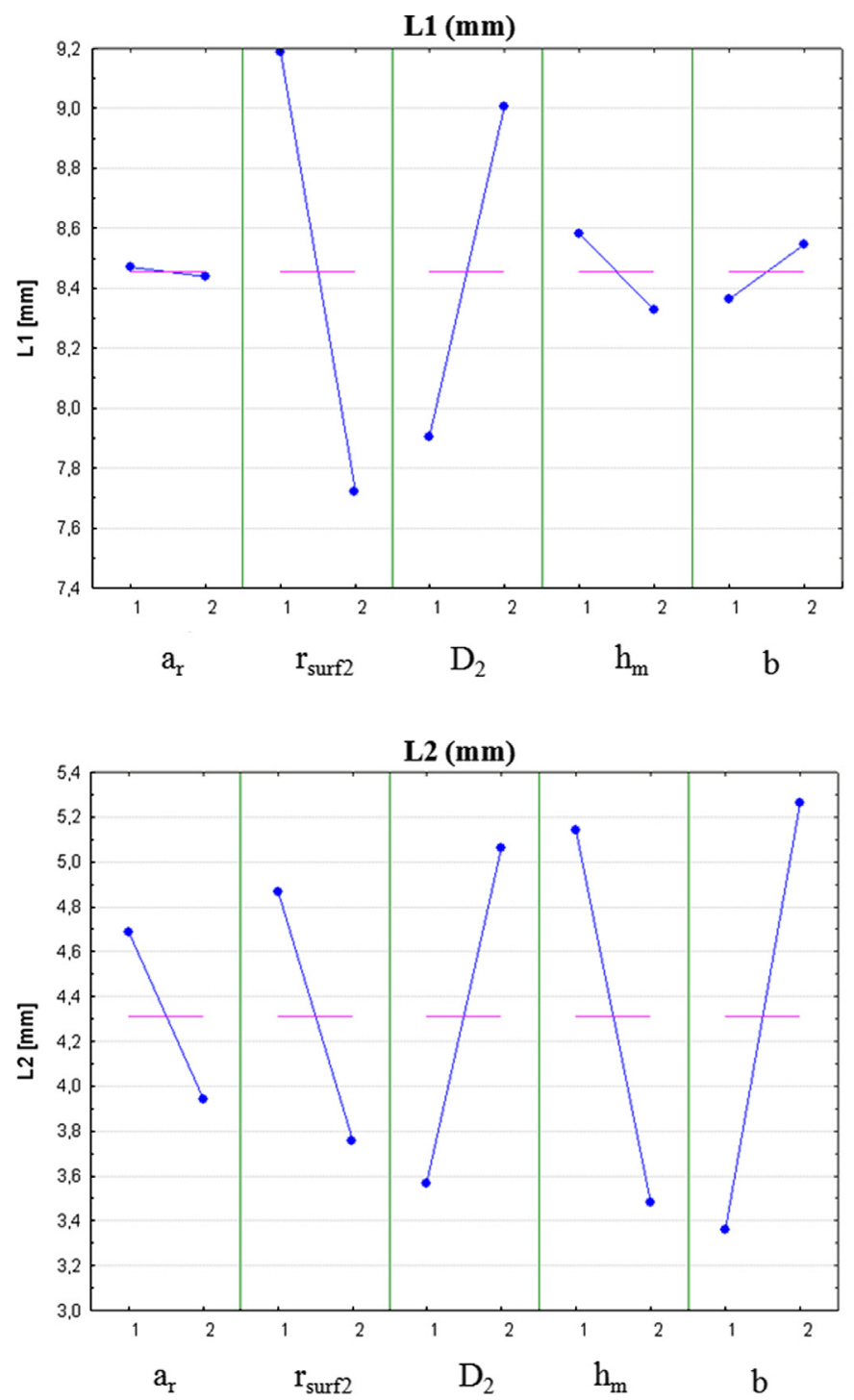

been used:

$A=A_{s}+\left(A_{l}-A_{s}\right) \cdot f l c 2 h s\left(T-T_{m}, \Delta T\right)$

where $A_{s}, A_{l}$ are respectively the properties of solid and liquid phase such as $\lambda, \rho$ and $c p$ and $\Delta T$ is the temperature interval of smoothing (100 K).

The data used for calculation are given in Table 5:

\subsection{Choice of the equivalent heat sources}

The development of numerical model is divided in three steps. First, the sources which represent laser alone are defined. Then the

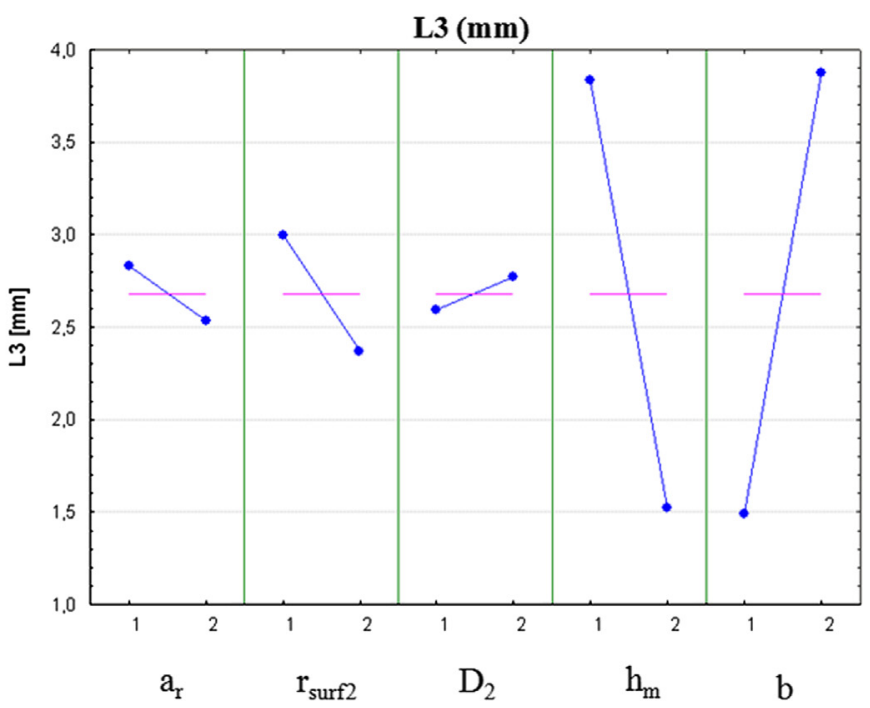

\section{L4 (mm)}

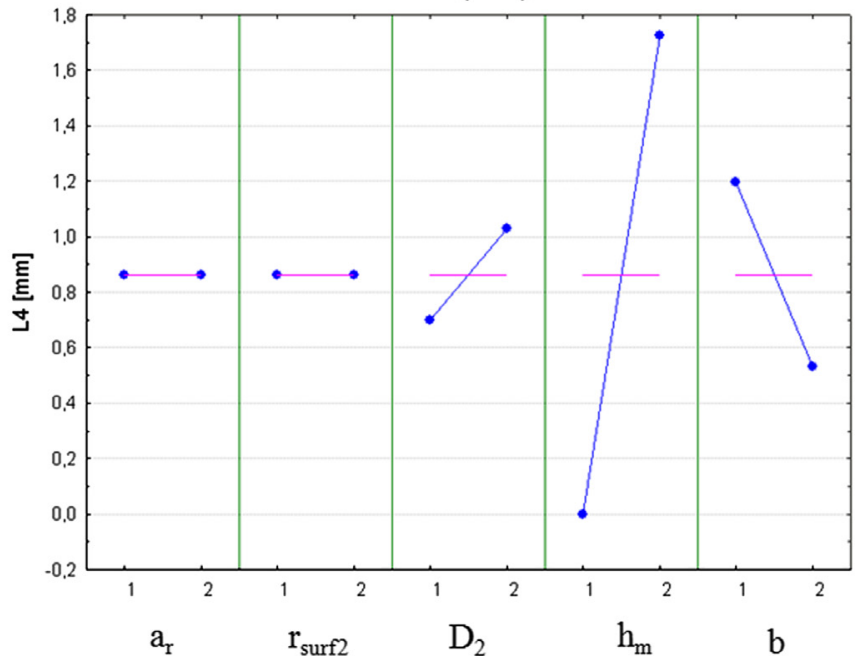

Fig. 9. Diagram of effects of influencing factors.

Table 6

Optimized parameters of heat sources.

\begin{tabular}{|c|c|c|c|c|c|c|c|}
\hline$A_{1}(\%)$ & $r_{\text {surf } 1}(\mathrm{~m})$ & $d z(\mathrm{~m})$ & $\eta_{v}(\%)$ & $r_{0}(\mathrm{~m})$ & $a_{r}(\mathrm{~m})$ & $a_{f}(\mathrm{~m})$ & $b(\mathrm{~m})$ \\
\hline 24 & $7 \times 10^{-4}$ & $7 \times 10^{-4}$ & 71 & $2.4 \times 10^{-3}$ & $7 \times 10^{-3}$ & $2 \times 10^{-3}$ & $7 \times 10^{-5}$ \\
\hline$c(\mathrm{~m})$ & $\lambda_{\mathrm{eq}}(\mathrm{W} / \mathrm{m} \mathrm{K})$ & $r_{1}(\mathrm{~m})$ & $r_{\text {surf } 2}(\mathrm{~m})$ & $A_{2}(\%)$ & $\eta(\%)$ & $D_{2}(\mathrm{~m})$ & $h_{m}(\mathrm{~mm})$ \\
\hline $9 \times 10^{-3}$ & 70 & $1.45 \times 10^{-3}$ & $7 \times 10^{-3}$ & 60 & 25.5 & $2.25 \times 10^{-2}$ & $2 \times 10^{-3}$ \\
\hline
\end{tabular}


heat sources corresponding to MIG process are identified. And finally, all of these sources are introduced into the hybrid laser IMIG model.

\subsubsection{Laser sources}

The focused laser beam is used in a keyhole mode. The energy contribution of laser is assumed by a combination [3] of Gaussian source with parietal supply:

$q_{\text {surf } 1}=\frac{P_{L} A_{1}}{2 \pi r_{\text {surf } 1}^{2}} e^{\left(-\frac{x^{2}+v^{2}}{2 r_{\text {surf } 1}^{2}}\right)} e^{\left(-\frac{w^{2}}{d z^{2}}\right)}$

and volumic Goldak conic source:

$Q_{1}=\frac{9 P_{L} \eta_{v}}{\pi h\left(r_{0}^{2}+r_{0} r_{1}+r_{1}^{2}\right)} e^{\left(-3 \frac{x^{2}+y^{2}}{r_{z}^{2}}\right)}[1-u(z+h)]$

where $r_{z}=r_{0}+\frac{r_{0}-r_{1}}{h} z, r_{0}$ melted zone radius when $z=0$, $h$ depth penetration, $r_{1}$ melted zone when $z=-h$ and $u(z+h)$ Heaviside function. $(v, w)$ are coordinate system for $q_{\text {surf } 1}$ position is defined as follows (Fig. 7).

$v=z \sin \beta+y \cos \beta \quad w=-y \sin \beta+z \cos \beta$

In Eq. (4) en (5) unknown parameters to be identified are $A_{1}, r_{0}$, $r_{1}, r_{\text {surf } 1}, d z$, and $\eta_{v}$.

\subsubsection{Metal inert gas (MIG) sources}

The power distribution of MIG [11] is modeled in following way. On the one hand, we consider that volumic energy is due to the heat input from melted droplets which is represented by a

Table 7

Statistical treatment of characteristic dimensions measured on experimental melted zones and their comparison with equivalent source model results.

\begin{tabular}{lcccccc}
\hline & $\mathrm{L}_{1}$ & $\mathrm{~L}_{2}$ & $\mathrm{~L}_{3}$ & $\mathrm{~L}_{4}$ & $\mathrm{~L}_{5}$ & $\mathrm{~L}_{6}$ \\
\hline $\bar{L}_{i}$ (measurement) & 8.84 & 3.62 & 1.97 & 2.12 & 1.14 & 1.54 \\
$\sigma\left(L_{i}\right)$ & 0.97 & 0.55 & 0.73 & 0.35 & 0.18 & 0.40 \\
$\sigma\left(\bar{L}_{i}\right)$ & 0.26 & 0.15 & 0.19 & 0.09 & 0.05 & 0.11 \\
$\pm 2 \times t_{\alpha} \times \sigma\left(\bar{L}_{i}\right)$ & 1.23 & 0.70 & 0.92 & 0.17 & 0.08 & 0.50 \\
$L_{i}+2 \times t_{\alpha} \times \sigma\left(\bar{L}_{i}\right)$ & 10.07 & 4.32 & 2.89 & 2.28 & 1.22 & 2.05 \\
$L_{i}-2 \times t_{\alpha} \times \sigma\left(\bar{L}_{i}\right)$ & 7.62 & 2.93 & 1.05 & 1.95 & 1.05 & 1.04 \\
$L_{i}$ (modeling) & 8.80 & 3.50 & 1.38 & 1.86 & 1.1 & 1.38 \\
\hline
\end{tabular}

a

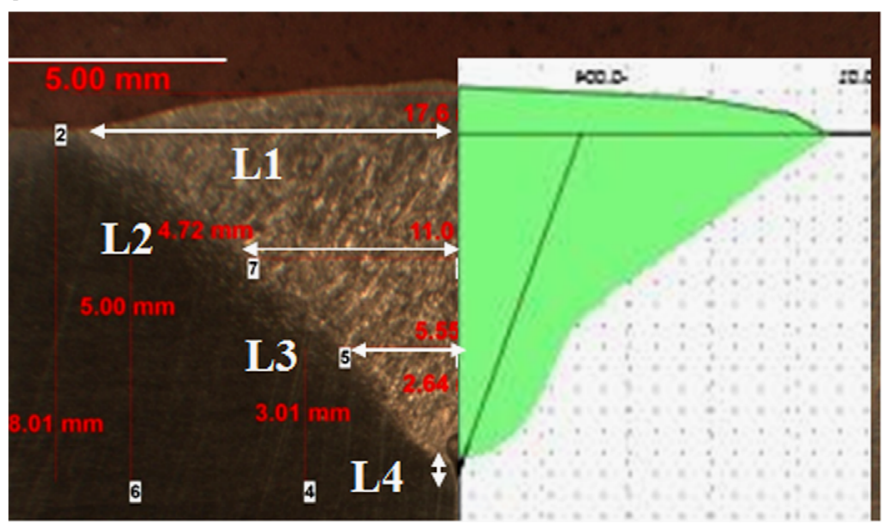

b

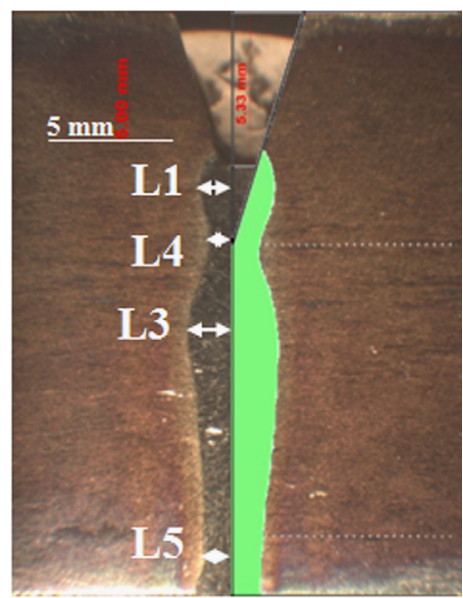

C

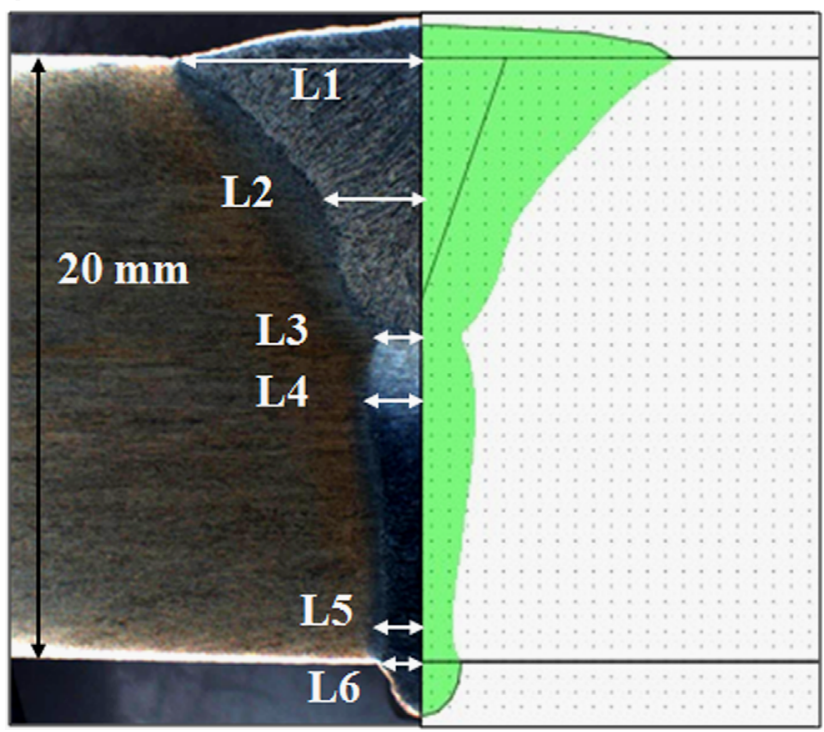

Fig. 10. Comparison between calculated and experimental geometries of the melted zones. 
double-ellipsoid source proposed by Goldak et al. [9,10]

$Q_{2 f}(x, y, z)=f_{f} \frac{6 \sqrt{3} \eta U I}{a_{f} b c \pi \sqrt{\pi}} e^{-3\left(\frac{x-D_{2}}{a_{f}}\right)^{2}} e^{-3\left(\frac{y}{b}\right)^{2}} e^{-3\left(\frac{z-h_{m}}{c}\right)^{2}}(x>0)$

$Q_{2 r}(x, y, z)=f_{r} \frac{6 \sqrt{3} \eta U I}{a_{r} b c \pi \sqrt{\pi}} e^{-3\left(\frac{x-D_{2}}{a_{r}}\right)^{2}} e^{-3\left(\frac{y}{b}\right)^{2}} e^{-3\left(\frac{z-h_{m}}{c}\right)^{2}}(x \leq 0)$

As a second point the surface energy is associated to the arc. This heat source is assumed to have a Gaussian heat
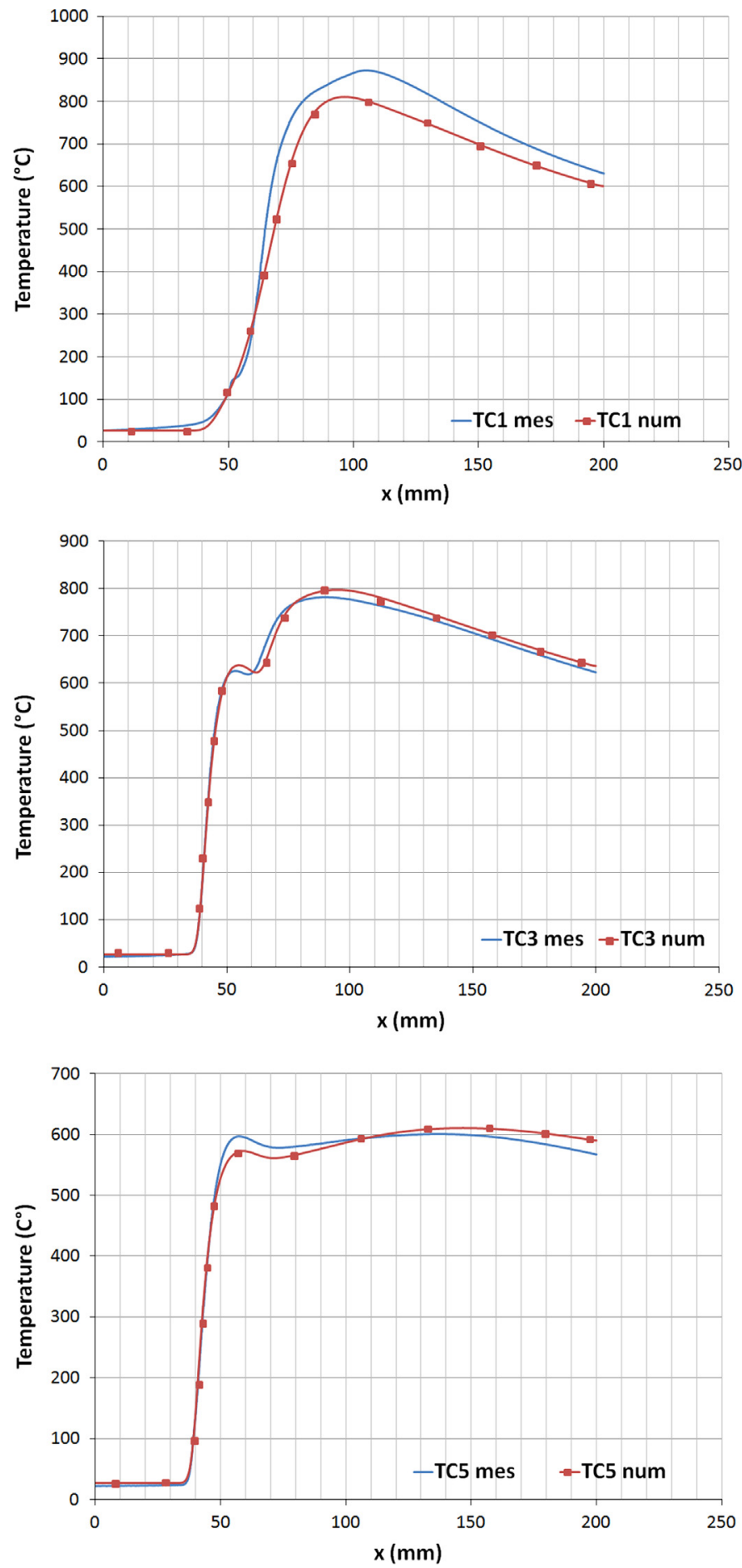

distribution [8]:

$q_{\text {surf } 2}=\frac{A_{2} U I}{2 \pi r_{\text {surf } 2}^{2}} e^{\left(-\frac{\left(x-D_{2}\right)^{2}+y^{2}}{2 r_{\text {surf } 2}^{2}}\right)}$

Parameters to be identified are $a_{r}, a_{f}, b, c, \eta, r_{\text {surf2 }}, h_{m}, D_{2}$ and $A_{2}$.

\subsubsection{Hybrid laser/MIG sources}

The setup of hybrid numerical model is based on both previous cases. The heat sources chosen for laser alone and MIG alone were
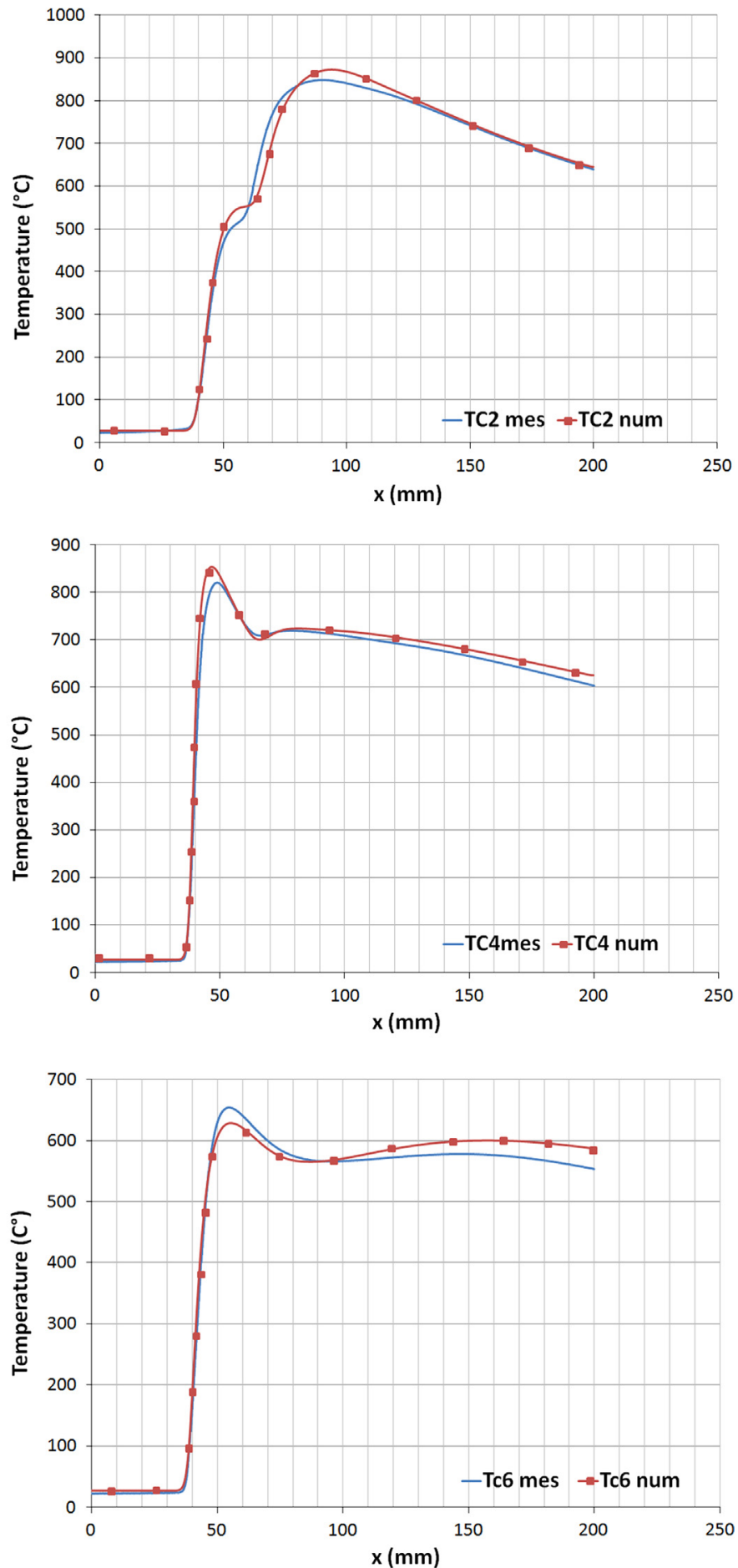

Fig. 11. Comparison between measured and calculated thermograms. 
used for the hybrid case and the heat parameters were identified by using the numerical exploratory designs method. In this case we consider a predefined geometry for a filler metal with a fixed inclination of filler front. This geometry was determined from experimental macrographies.

\section{Identification of equivalent heat source parameters}

The identification process is applied in the same way for three numerical models. We use a method of parameter optimization, simple to implement and robust, founded on the numerical exploratory designs method [12]. From the numerical model, we define a list of influencing factors (IF) and response functions (RF) which allow to determine all possible combinations (a design matrix) of input parameters and to organize the simulations. Using a limited number of calculations, we evaluate the effects of IF (parameters of analytical expressions of equivalent heat sources) on RF (geometrical characteristics of the melted zone).The analysis of response direction and amplitudes allows to make adjustments of the IF values in order to attain the fixed limit of relative error between the experiments and calculations. The procedure can be represented by the following diagram (Fig. 8).

\section{Results and discussion}

A sensitivity study of equivalent heat source parameters is used to determine the influence of each parameters $\left(a_{f}, a_{r}, b, c \ldots\right)$ on the geometric dimensions $\left(\mathrm{L}_{1}, \mathrm{~L}_{2}, \mathrm{~L}_{3}\right.$..) which describe the shape of the weld macrographs in transverse direction, as shows Fig. 9. For the numerical design matrix we use a fractional design $2^{5-2}$ (which contains all combinations between the two values of the three analyzed factors). As an example, Fig. 9 shows the effect diagrams in the case of MIG only, which represent the amplitude and the direction of the influencing factors on each of response functions.

The analysis of these effects indicates that:

- The RF $\mathrm{L}_{4}$ is strongly influenced by the position of Goldak heat source relatively to chamfer bottom $\left(h_{m}\right)$.

- The increase of arc heat source spread $\left(R_{\text {surf } 2}\right)$ leads to the increase of $\mathrm{L}_{1}$ et $\mathrm{L}_{2}$.

- $R_{\text {surf2 }}$ has an inverse effect on $\mathrm{L}_{1}$ and $\mathrm{L}_{2}$ : if $R_{\text {surf2 }}$ increases $\mathrm{L}_{1}$ and $\mathrm{L}_{2}$ decrease.

- Laser-arc distance $\left(D_{2}\right)$ also affects $\mathrm{L}_{1}$ and $\mathrm{L}_{2}$ : if $D_{2}$ increases $\mathrm{L}_{1}$ and $\mathrm{L}_{2}$ increase.

- $x$-axis spread of Goldak heat source $\left(a_{r}\right)$ has a low influence on all object functions.

The identification of heat source parameters in hybrid case is based on models of laser and MIG. These parameters are given in Table 6.

Fig. 10 shows calculated and experimental crosscuts of the welds for hybrid (c), laser (b) and MIG (a) cases.

The dimensions of the fusion zone obtained from the heat transfer study have been compared to the measured values. As it can be seen in Fig. 10, the melted zone shape obtained from the numerical modeling correlates well with the experimental results. Table 7 gives an example of results obtained in hybrid welding case after fitting heat source parameters.

It can be observed that all the calculated values enter in the confidence interval determined for experimental values.

The temperature fields calculated in the work piece were compared with thermocouple measurements and show good concordance (Fig. 11). It can be seen that in function of thermocouple
Table 8

The comparison experimental and calculated maximum temperatures.

\begin{tabular}{|c|c|c|c|c|c|c|}
\hline \multirow[t]{2}{*}{$\mathrm{TC}$} & \multicolumn{2}{|c|}{$T_{\max } \operatorname{mes}[\mathrm{K}]$} & \multicolumn{2}{|c|}{$T_{\max } \operatorname{num}[\mathrm{K}]$} & \multicolumn{2}{|c|}{$\Delta T[\mathrm{~K}]$} \\
\hline & Laser & MIG & Laser & MIG & Laser & MIG \\
\hline 1 & - & 1144 & - & 1084 & - & 60 \\
\hline 2 & - & 1119 & - & 1145 & - & -26 \\
\hline 3 & 899 & 1053 & 910 & 1069 & -11 & -16 \\
\hline 4 & 1092 & 991 & 1126 & 997 & -34 & -6 \\
\hline 5 & 869 & 872 & 845 & 883 & 24 & -11 \\
\hline 6 & 927 & 850 & 901 & 873 & 26 & -23 \\
\hline
\end{tabular}

position, it responds on MIG or laser heat source passage. The TC1 situated close to the top of the work piece responds only on MIG source passage without detecting the laser source. TC2 and TC3 placed in the middle of work piece register two pikes (Fig. 11): the first one induced by laser and the second one induced by MIG. The shift between two pikes reflects the distance between the laser head and the MIG torch. The TC4, TC5 and TC6 situated in the lower half of the work piece are mostly sensible to laser passage: they show one pick due to laser followed by a plateau corresponding to the diffusion of heat from MIG.

The comparison of pick values of experimental and calculated thermograms (Table 8 ) showed $\leq 5 \%$ relative error.

We notice that the thermal levels are found by using the parameters defined before for the model conception which was initially validated by experimental macrographs. The difference between measured and calculated thermograms can be linked from one hand to the model errors as the numerical model does not take into account thermocouples holes and, in another hand, from the simplifying assumptions which present partially physical phenomena involved.

\section{Conclusion}

In the present study, a 3D quasi-steady state model of heat transfer for welding duplex steel UR2507Cu with Y shaped chamfer is developed to analyze hybrid laser/MIG welding. Using the numerical experimental designs method associated to the numerical model, the equivalent heat source parameters were estimated and adjusted to reproduce the characteristics of the melted zone. The model results are satisfying since we obtain low difference ( $<9 \%$ ) between model and measurements for the melted zone dimensions and also for the temperature inside the work piece. These results allow us to validate to choice of equivalent heat sources for heat supply of hybrid welding process. This information can be used to solve thermomechanical problem. In the following, we look for developing a methodology based on the experimental designs which gives the possibility to link the operating parameters (laser power, welding velocity ...) to simulated geometrical values of the melted zone.

\section{Acknowledgement}

The authors are grateful for the funding provided by the A.N.R for "SISHYFE" project.

\section{References}

[1] EW Reutzel, SM Kelly, RP Martukanitz, MM Bugarewics, P Michaleris, LaserGMA hybrid welding: process monitoring and thermal modelling. In: SA David et al. (Eds.),Proceeding of the seventh international conference on trends in welding research, Callaway Gardens Resort, Pine Mountain, Georgia, USA (2005) 143-148. 
[2] Le Guen E, Le Masson P, Fabbro R, Carin M, et al. 3D heat transfer model of hybrid laser Nd:Yag-MA welding of S355 steel and experimental validation. Heat \& Mass Transfer 2011:1313-22.

[3] Bidi L, Mattei S, Cicala E, Andrzejewski H, Le Masson P, Schroeder J. The use of exploratory experimental designs combined with thermal numerical modeling to obtain a predictive tool for hybrid laser/MIG welding and coating processes. Optics \& Laser Technology 2011:537-45.

[4] Cho JH, Na SJ. Three dimensional analysis of molten pool in GMA-laser hybrid welding. Welding Journal 2009.

[5] Gao Z, Wu Y, Huang J. Analysis of weld pool dynamic during stationary laserMIG hybrid welding. Advanced Manufacturing Technology 2009.

[6] Zhou J, Tasi HL. Modeling of transport phenomena in hybrid laser-MIG keyhole welding. International Journal of Heat and Mass Transfer 2008.

[7] COMSOL Multiphysics users guide, version 3.5a; 2007.
[8] Bonacina C, Comini G, Fasano A, Primocerio M. Numerical solutions of phasechange problems. International Journal of Heat and Mass Transfer 1973;16:1825-32.

[9] Goldak JA, Chakravarta A, Bibby MJ. A new finite element model for welding heat source. Metallurgical and Materials Transactions B 1984:13:299-305.

[10] Goldak J, Bibby M, Morre J, House R, Patel B. Computer modelling heat flow in welds. Metallurgical and Materials Transactions B 1986;17b.

[11] Xu G, Wu C. Numerical analysis of weld pool geometry in globular-transfer gas metal arc welding. Frontiers of Materials Science in China 2007;1(1):24-9.

[12] Bendaoud I, Matteï S, Tomashchuk I, Andrzejewski H, Sallamand P, Mathieu A et al. simulation de l'apport de chaleur du procédé de soudage Hybride Laser MIG par l'approche sources équivalentes. Congrès Français de Thermique, Bordeaux-France 2012:649-56. 